\title{
Aspectos clínico-patológicos e laboratoriais do envenenamento experimental por Bothrops alternatus em bovinos ${ }^{1}$
}

\author{
Saulo A. Caldas ${ }^{2}$, Carlos H. Tokarnia ${ }^{3}$, Ticiana N. França ${ }^{4}$, Marilene F. Brito ${ }^{5}$, \\ Flávio A.S. Graça ${ }^{6}$, Cleide D. Coelho ${ }^{7}$ e Paulo V. Peixoto ${ }^{3}$
}

\begin{abstract}
Caldas S.A., Tokarnia C.H., França T.N., Brito M.F., Graça F.A.S., Coelho C.D. \& Peixoto P.V. 2008. [Clinic and pathological and laboratory aspects of experimental poisoning by Bothrops alternatus venom in cattle.] Aspectos clínicopatológicos e laboratoriais do envenenamento experimental por Bothrops alternatus em bovinos. Pesquisa Veterinária Brasileira 28(6):303-312. Projeto Sanidade Animal Embrapa/ UFRRJ, Seropédica, RJ 23890-000, Brazil. E-mail: saulo-andrade@ bol.com.br

The aim of this study was to determine the clinical-pathological alterations and laboratory findings in cattle inoculated with Bothrops alternatus venom, with the intention of providing information for the establishment of diagnosis and differential diagnosis procedures, as well as to elucidate some obscurities observed in the pertinent literature. The lyophilized venom was diluted in $1 \mathrm{ml}$ of physiologic solution. It was administered to 5 bovines by the subcutaneous route at doses of $0.0625,0.125$ and $0.25 \mathrm{mg} / \mathrm{kg}$ body weight, and to 2 bovines by the intramuscular route at doses of 0.25 e $0.45 \mathrm{mg} / \mathrm{kg}$. Six bovines died and the only animal that survived, who had subcutaneously received the venom at a dose of $0.0625 \mathrm{mg} / \mathrm{kg}$, recovered. The first clinical signs were observed from $25 \mathrm{~min}$ to $5 \mathrm{~h} 30 \mathrm{~min}$ after the inoculation. The clinical evolution time varied from 7 hours 18 minutes to 92 hours. Regardless of the dose, the clinical picture was characterized by swelling (hemorrhage/hematoma) at the site of inoculation, increase in bleeding time and capillary refill time, paleness of mucous membranes and apathy. The laboratory exams revealed progressive normocytic normochromic anemia, thrombocytopenia, reduction in fibrinogen and total plasma proteins, decreased hematocrit and hemoglobin, and slight increase in creatine kinase and lactate dehydrogenase. When subjected to necropsy, the animals that received the venom through the subcutaneous route showed large hematomas and hemorrhagic areas in the subcutaneous tissue, extending from the site of inoculation. The animals in which inoculation was performed intramuscularly exhibited, in addition, intramuscular hemorrhage. The left endocardium showed extensive hemorrhagic lesions, and petechiae were found on the serosae of rumen, omasum, abomasum and gall bladder. The colon, rectum and perirenal areas were surrounded by clotted blood in three animals. Besides hemorrhage, the histological examination revealed hemorrhage and coagulative muscle necrosis in the vicinities of the inoculation site in the
\end{abstract}

\footnotetext{
${ }^{1}$ Recebido em 12 de dezembro de 2007.

Aceito para publicação em 28 de março de 2008.

2 Parte da Dissertação de Mestrado no Curso de Ciências Veterinárias, Universidade Federal Rural do Rio de Janeiro (UFRRJ). *Autor para correspondência: saulo-andrade@bol.com.br

${ }^{3}$ Depto Nutrição Animal e Pastagens, Instituto de Zootecnia, UFRRJ, Seropédica, RJ 23890-000, Brasil.

${ }^{4}$ Centro de Ciências Biológicas e da Saúde, Faculdade de Medicina Veterinária, Universidade Estácio de Sá, Estr. Boca do Mato 850, Vargem
}

Pequena, Rio de Janeiro, RJ 22783-320; e Depto Cirurgia, Setor de Cirurgia Experimental, Faculdade de Medicina, Universidade Federal do Rio de Janeiro (UFRJ), Rio de Janeiro, RJ 21944-970, Brasil.

${ }^{5}$ Depto Epidemiologia e Saúde Pública, Instituto de Veterinária, UFRRJ, Seropédica, RJ.

${ }^{6}$ Depto Clínica de Animais de Produção, Universidade Castelo Branco, Avenida Brasil 9727, Penha, Rio de Janeiro, RJ 21021-020.

${ }^{7}$ Doutoranda do Curso de Pós-Graduação em Ciências Veterinárias, UFRRJ, Seropédica, RJ, Brasil. 


\begin{abstract}
animals that received the venom by the intramuscular route. These lesions were mild in the muscles close to the site of inoculation in the animals inoculated by the subcutaneous route. The swelling on the site of inoculation and its surroundings was a consequence of blood accumulation and not merely edema. Myoglobinuria and gross or microscopic lesions were not observed in the kidneys. This study indicates that $B$. alternatus can lead adult bovines to death if they release all their venom during a bite. Conversely, since venomous ophidians can control the amount of poison they inoculate and they probably do not identify bovines as potential preys, it is likely that the number of accidents involving this species is small, which is in agreement with the findings of the majority of the centers for anatomical-pathological diagnosis in Brazil.
\end{abstract}

INDEX TERMS: Bothrops alternatus, cattle, pathology, symptoms.

RESUMO.- Esse estudo teve como objetivo determinar as alterações clínico-patológicas e os achados laboratoriais em bovinos inoculados com a peçonha de Bothrops alternatus, no intuito de fornecer subsídios para o estabelecimento do diagnóstico e do diagnóstico diferencial, bem como esclarecer pontos obscuros da literatura pertinente. O veneno liofilizado foi diluído em $1 \mathrm{ml}$ de solução fisiológica e administrado a cinco bovinos, por via subcutânea, nas doses de 0,0625, 0,125 e 0,25 mg/kg e a dois outros, por via intramuscular, nas doses de 0,25 e 0,45 mg/kg. Seis bovinos foram a óbito e um que recebeu a dose de $0,0625 \mathrm{mg} / \mathrm{kg}$, por via subcutânea, recuperou-se. Os sinais clínicos tiveram início entre 25 minutos a 5 horas 30 minutos após a inoculação. O período de evolução variou de 7 horas 18 minutos a 66 horas 12 minutos. Um animal recuperou-se após 92 horas. O quadro clínico, independentemente das doses, caracterizou-se por aumento de volume (hemorragia/hematoma) no local da inoculação, tempo de sangramento aumentado, mucosas hipocoradas e apatia. O exame laboratorial revelou progressiva anemia normocítica normocrômica, trombocitopenia, redução de fibrinogênio e proteínas plasmáticas totais, hematócrito e hemoglobina diminuídos, além de leve aumento dos níveis de creatinaquinase e desidrogenase lática. Á necropsia, havia, a partir do local da inoculação, extensos hematomas e áreas de hemorragia no tecido celular subcutâneo dos animais que receberam o veneno por via subcutânea; nos animais inoculados por via intramuscular, adicionalmente, havia hemorragia intramuscular. O endocárdio esquerdo apresentava extensas hemorragias e verificaramse petéquias na serosa do rúmen e do omaso e na mucosa do abomaso e da vesícula biliar. Em cinco animais, o cólon, reto e região perirrenal estavam envoltos por coágulos de sangue. Ao exame histológico observou-se, além do quadro hemorragíparo, necrose muscular coagulativa, acompanhada de hemorragia, no entorno do local da inoculação nos animais que receberam o veneno por via intramuscular; essa lesão era discreta nos músculos próximos ao local de inoculação subcutânea. Nos bovinos deste estudo, o aumento de volume observado no local de inoculação e adjacências era constituído por sangue e não edema. Não foram observadas mioglobinúria, nem lesões macro ou microscópicas significativas nos rins. Este estudo indica que exemplares de $B$. alternatus, caso inoculem todo seu veneno, poderiam levar bovinos adultos à morte. Por outro lado, pelo fato de ofídios serem capazes de regular a quantidade de veneno inoculada e, possivelmente, não considerarem bovinos como presa potencial, é provável que o número de acidentes nessa espécie seja pequeno, o que está de acordo com o observado na maioria dos centros diagnóstico anátomo-patológico no país.

TERMOS DE INDEXAÇÃO: Bothrops alternatus, bovinos, patologia, sintomas.

\section{INTRODUÇÃO}

Os acidentes ofídicos, em geral, são considerados de grande importância como causa de mortalidade em animais de fazenda. Em relação aos bovinos, parte dos autores deixam em aberto a questão da importância dos acidentes ofídicos (Araújo et al. 1963), outros acreditam que o número de bovinos que morrem no Brasil, em função de picadas-de-cobra, seja muito alto (Belluomini et al. 1983, Novaes et al. 1986, Bicudo 1999), e ainda outros acham que são pouco freqüentes (Grunert1967, Grunert \& Grunert 1969, Tokarnia \& Peixoto 2006)

Foram realizados muitos experimentos com o veneno das serpentes do gênero Bothrops em bovinos, sem descrição detalhada do quadro clínico-patológico (Araújo \& Belluomini 1960/62, Belluomini 1983). Só Novaes et al. (1986) fornecem alguns dados sobre o quadro clíniconecroscópico em bovinos, sem descrição das alterações histológicas, envenenados experimentalmente através de picada ou injeção do veneno de diversas espécies de Bothrops, enquanto Oliveira et al. (2004a,b) relatam os achados histopatológicos em 2 bovinos e as alterações sanguíneas em 5 vacas envenenadas através da inoculação do veneno de $B$. alternatus.

De acordo com os experimentos executados por Araújo et al. (1963), Bothrops alternatus é uma das serpentes mais peçonhentas que ocorre com maior freqüência em terras mais elevadas e secas, desde o sul de Goiás, Minas Gerais e Mato Grosso do Sul até o extremo sul do Brasil (Fig.1) (Barraviera 1999).

No Brasil, só há descrição de dois acidentes fatais em bovinos determinados por serpentes do gênero Bothrops, na Bahia e no Rio Grande do Sul (Grunert \& Grunert 1969, Menezes 1995/96). 


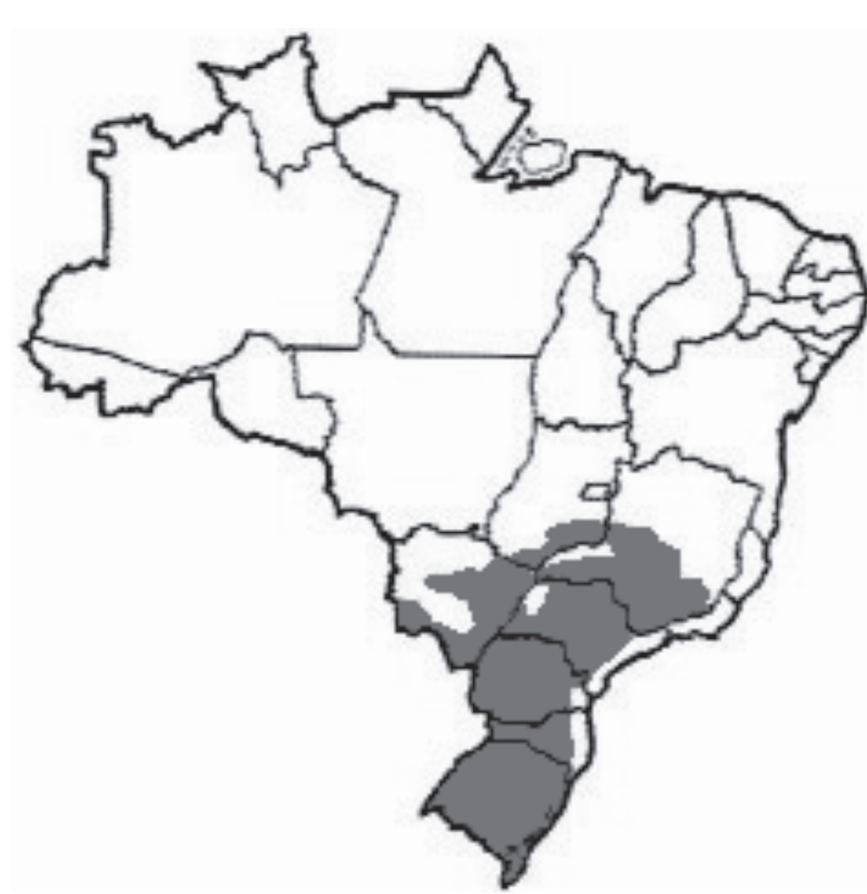

Fig.1. Distribuição de Bothrops alternatus (Melgarejo 2003).

Esse estudo tem como objetivo determinar, com maior precisão, as alterações clínico-patológicas e laboratoriais em bovinos inoculados com peçonha de Bothrops alternatus, com a finalidade de fornecer subsídios que possam facilitar o estabelecimento do diagnóstico e do diagnóstico diferencial dessa condição.

\section{MATERIAL E MÉTODOS}

Os experimentos foram realizados entre junho de 2006 e março de 2007 nas instalações do Setor de Anatomia Patológica, Projeto Sanidade Animal Embrapa/UFRRJ. O estudo experimental foi aprovado pela comissão de ética do Curso de Pós-Graduação em Ciências Veterinárias da UFRRJ.

Foram utilizados 9 bovinos, machos, mestiços, clinicamente sadios, com idades de 12 a 25 meses e pesos entre 96,5 e 198 $\mathrm{kg}$. Dois desses bovinos foram utilizados como controle. Os animais foram previamente tratados contra endo e ectoparasitos e adaptados ao local. A dieta era constituída de capim picado, feno e ração concentrada para a manutenção, sal com sulfato de cobre e água à vontade. Os bovinos foram mantidos em baias individuais de alvenaria de 3,0m x 4,0m.

O veneno, colhido por extração manual, de exemplar capturado no município de Itaboraí, RJ, foi liofilizado (dessecado a vácuo e mantido congelado a $10^{\circ} \mathrm{C}$ negativos) no Instituto de Biologia do Exército do Rio de Janeiro. A DL 50 foi preparada com o veneno de $B$. alternatus, na divisão de Zoologia Médica do Instituto Vital Brasil, Niterói, RJ. No momento da inoculação o veneno foi reconstituído em $1 \mathrm{ml}$ de soro fisiológico.

O experimento piloto foi realizado em um animal e os demais foram executados a partir dos resultados obtidos nesse experimento (experimentos auto-direcionados). Os animais foram submetidos à inoculação do veneno de $B$. alternatus, pela via subcutânea, nas doses de $0,0625 \mathrm{mg} / \mathrm{kg}, 0,125 \mathrm{mg} / \mathrm{kg}$, $0,25 \mathrm{mg} / \mathrm{kg}$ e pela via intramuscular nas doses de 0,25 e $0,45 \mathrm{mg} /$ $\mathrm{kg}$, na região posterior da coxa direita, à altura do músculo semitendinoso, na profundidade de $6 \mathrm{~mm}$, no caso da inoculação subcutânea e $2 \mathrm{~cm}$ na inoculação intramuscular. Um animal controle recebeu solução salina inoculada por via subcutânea e o outro por via intramuscular. Os bovinos foram acompanhados clinicamente, a cada 2 horas, até o óbito ou por um período de até 7 dias.

Foram feitas colheitas de sangue (hemograma completo, leucometria global e leucometria específica, contagem de plaquetas e de reticulócitos, determinações de fibrinogênio e proteínas plasmáticas totais) e urina de cada animal. As amostras de sangue destinadas à bioquímica sérica (glicose, uréia, creatinina, proteínas séricas totais, aspartato aminotransferase, alamina aminotransferase, gama GT, creatinaquinase e dehidrogenase láctica) foram colhidas em frascos que permitiram a formação e retração do coágulo, com exceção daquelas destinadas ao coagulograma (tempo de ativação da protrombina, tempo de tromboplastina parcial ativada e tempo de sangramento) e dosagem de glicose, as quais foram colocadas em frascos com citrato de sódio e fluoreto de sódio, respectivamente. Já as amostras destinadas à realização de hemograma foram colocadas em frascos com ácido etilenodiaminotetra-acético (EDTA) a 10\%. As amostras foram colhidas nos tempos 0, 2, 6, 12, 24 e 48 horas após a inoculação; no animal que sobreviveu uma última colheita foi realizada 120 horas após a inoculação. As amostras de urina foram obtidas por estimulação prepucial, colhidas e acondicionadas em frascos coletores estéreis, imediatamente colocadas sob refrigeração e processadas num tempo médio de 6 horas após a coleta.

As necropsias foram realizadas imediatamente após a morte dos animais, com colheita de encéfalo, medula, hipófise, globo ocular, fragmentos de coração, pulmões, fígado, vesícula biliar, rins, baço, rúmen, retículo, omaso, abomaso, intestinos, bexiga, parótida, tireóide, adrenal, pâncreas, junção costocondral, testículos, músculo masseter, língua, diafragma, intercostal, cervical, bíceps, psoas, longíssimo dorsal, semitendinoso e semimembranoso do membro inoculado e contra-lateral, tecido celular subcutâneo com pele do local da inoculação e contralateral. As amostras foram fixadas em formol a 10\%, com exceção dos fragmentos de músculos, que só foram fixadas duas horas após. Os fragmentos sofreram processamento de rotina para histopatologia (foram desidratados em álcool absoluto, tratados com xilol, embebidos e incluídos em parafina, cortados a $5 \mu$ e corados pela hematoxilina-eosina).

\section{RESULTADOS}

Os principais dados sobre o delineamento experimental e o desfecho encontram-se no Quadro 1.

\section{Dose letal e evolução clínica}

Dos sete bovinos que receberam doses potencialmente letais, seis morreram (doses de 0,125, 0,25 e 0,45mg/kg). O período de evolução variou de 7 horas 18 minutos a 66 horas 12 minutos. Um animal começou a se recuperar após ter mostrado sintomas de envenenamento durante 92 horas $(0,0625 \mathrm{mg} / \mathrm{kg})$.

\section{Início dos sintomas}

Os bovinos que receberam doses letais do veneno de $(0,125$ e $0,25 \mathrm{mg} / \mathrm{kg}$ de peso), por via subcutânea, apre- 
Quadro 1. Delineamento experimental e desfecho

\begin{tabular}{|c|c|c|c|c|c|c|c|c|}
\hline $\begin{array}{c}\text { Bovino } \\
\text { no. }\end{array}$ & Peso & Dose & $\begin{array}{l}\text { Dose total } \\
\text { administrada }\end{array}$ & $\begin{array}{c}\text { Vias de } \\
\text { inoculação }\end{array}$ & $\begin{array}{l}\text { Data e hora de } \\
\text { inoculação }\end{array}$ & $\begin{array}{l}\text { Início dos sin- } \\
\text { tomas após a } \\
\text { inoculação }\end{array}$ & Evolução & Desfecho \\
\hline $\begin{array}{l}5711 \\
\text { Macho }\end{array}$ & $187 \mathrm{~kg}$ & $0,25 \mathrm{mg} / \mathrm{kg}$ & $46,7 \mathrm{mg} / 1 \mathrm{ml}$ & Subcutânea & 6.6.06 13h43 & 25 minutos & $\begin{array}{l}7 \text { horas e } \\
18 \text { minutos }\end{array}$ & Morte \\
\hline $\begin{array}{l}5713 \\
\text { Macho }\end{array}$ & 152 kg & $0,25 \mathrm{mg} / \mathrm{kg}$ & $38 \mathrm{mg} / 1 \mathrm{ml}$ & Subcutânea & 12.9./06 10h00 & $\begin{array}{c}1 \text { hora e } \\
5 \text { minutos }\end{array}$ & $\begin{array}{l}18 \text { horas e } \\
10 \text { minutos }\end{array}$ & Morte \\
\hline $\begin{array}{l}5714 \\
\text { Macho }\end{array}$ & 146 kg & $0,125 \mathrm{mg} / \mathrm{kg}$ & $18,25 \mathrm{mg} / 1 \mathrm{ml}$ & Subcutânea & $12.9 .0611: 00$ & $\begin{array}{l}1 \text { hora e } \\
7 \text { minutos }\end{array}$ & $\begin{array}{l}66 \text { horas } \\
12 \text { minutos }\end{array}$ & Morte \\
\hline $\begin{array}{l}5715 \\
\text { Macho }\end{array}$ & 115 kg & $0,125 \mathrm{mg} / \mathrm{kg}$ & $14,37 \mathrm{mg} / 1 \mathrm{ml}$ & Subcutânea & $5.12 .0610 \mathrm{~h} 20$ & $\begin{array}{c}1 \text { hora e } \\
16 \text { minutos }\end{array}$ & $\begin{array}{l}14 \text { horas e } \\
10 \text { minutos }\end{array}$ & Morte \\
\hline $\begin{array}{l}5716 \\
\text { Macho }\end{array}$ & 129 kg & $0,0625 \mathrm{mg} / \mathrm{kg}$ & $8,0625 \mathrm{mg} / 1 \mathrm{ml}$ & Subcutânea & $5.12 .0611 \mathrm{~h} 25$ & $\begin{array}{c}5 \text { horas e } \\
30 \text { minutos }\end{array}$ & 92 horas & Recuperou-se \\
\hline $\begin{array}{l}5717 \\
\text { Macho }\end{array}$ & 138 kg & $0,45 \mathrm{mg} / \mathrm{kg}$ & $62,1 \mathrm{mg} / 1 \mathrm{ml}$ & Intramuscular & 21.3.07 10h50 & 35 minutos & $\begin{array}{l}9 \text { horas e } \\
40 \text { minutos }\end{array}$ & Morte \\
\hline $\begin{array}{l}5718 \\
\text { Macho }\end{array}$ & $96,5 \mathrm{~kg}$ & $0,25 \mathrm{mg} / \mathrm{kg}$ & $24,125 \mathrm{mg} / 1 \mathrm{ml}$ & Intramuscular & 21.3.07 10h57 & 55 minutos & $\begin{array}{l}33 \text { horas e } \\
50 \text { minutos }\end{array}$ & Morte \\
\hline $\begin{array}{l}5712 \\
\text { Macho }\end{array}$ & 187 kg & $\begin{array}{l}1 \text { ml solução } \\
\text { fisiológica }\end{array}$ & $\begin{array}{l}1 \text { ml solução } \\
\text { fisiológica }\end{array}$ & Intramuscular & 6.6.06 13h52 & - & - & Controle \\
\hline $\begin{array}{l}5564 \\
\text { Fêmea }\end{array}$ & 167 kg & $\begin{array}{l}1 \text { ml solução } \\
\text { fisiológica }\end{array}$ & $\begin{array}{l}1 \text { ml solução } \\
\text { fisiológica }\end{array}$ & Subcutânea & 21.3.07 11h05 & - & - & Controle \\
\hline
\end{tabular}
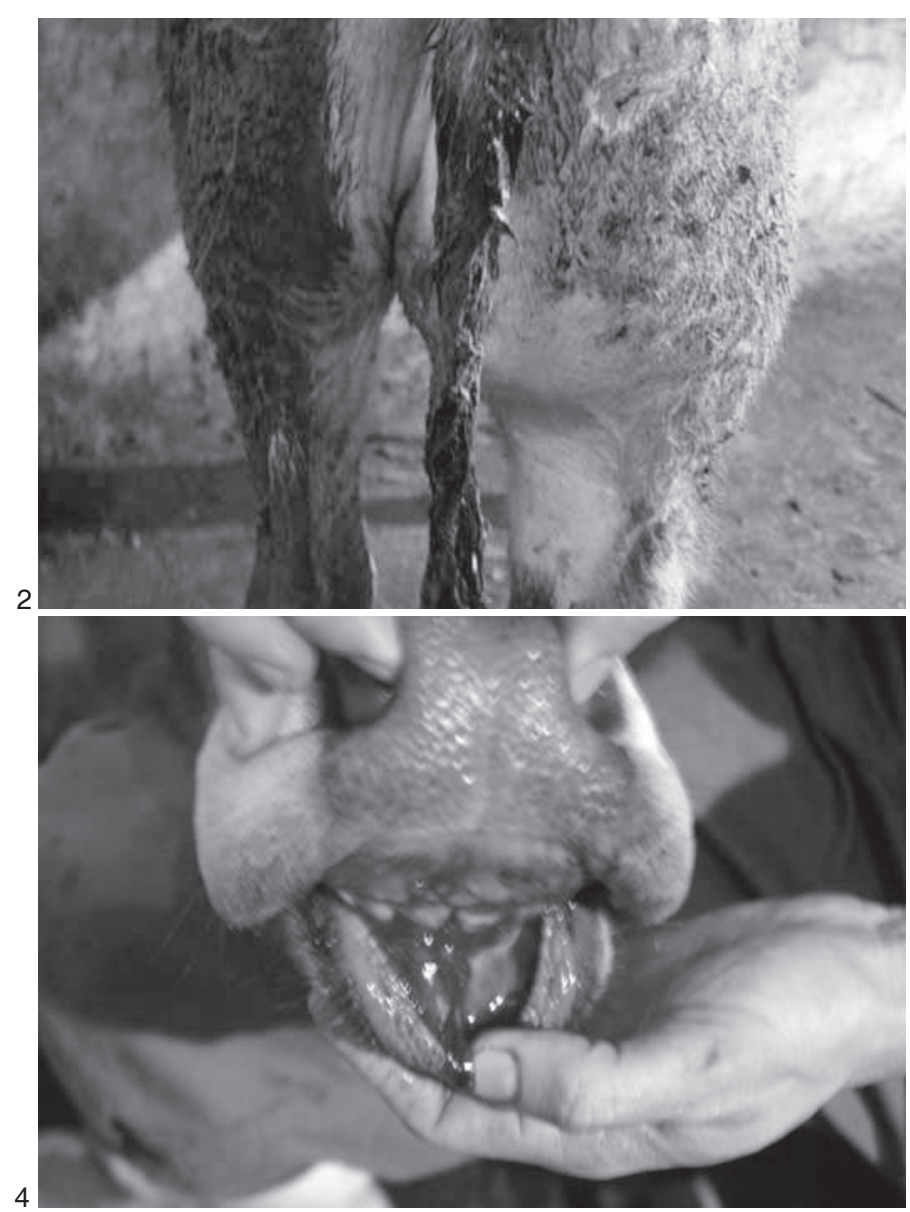

Fig.2. Hematoma subcutâneo no membro em que foi inoculado o veneno por via subcutânea. Notar a marcada assimetria entre os membros (Bovino 5716).

Fig.4. Sangramento em lesão prévia da gengiva que se reiniciou após inoculação subcutânea do veneno (Bovino 5713).

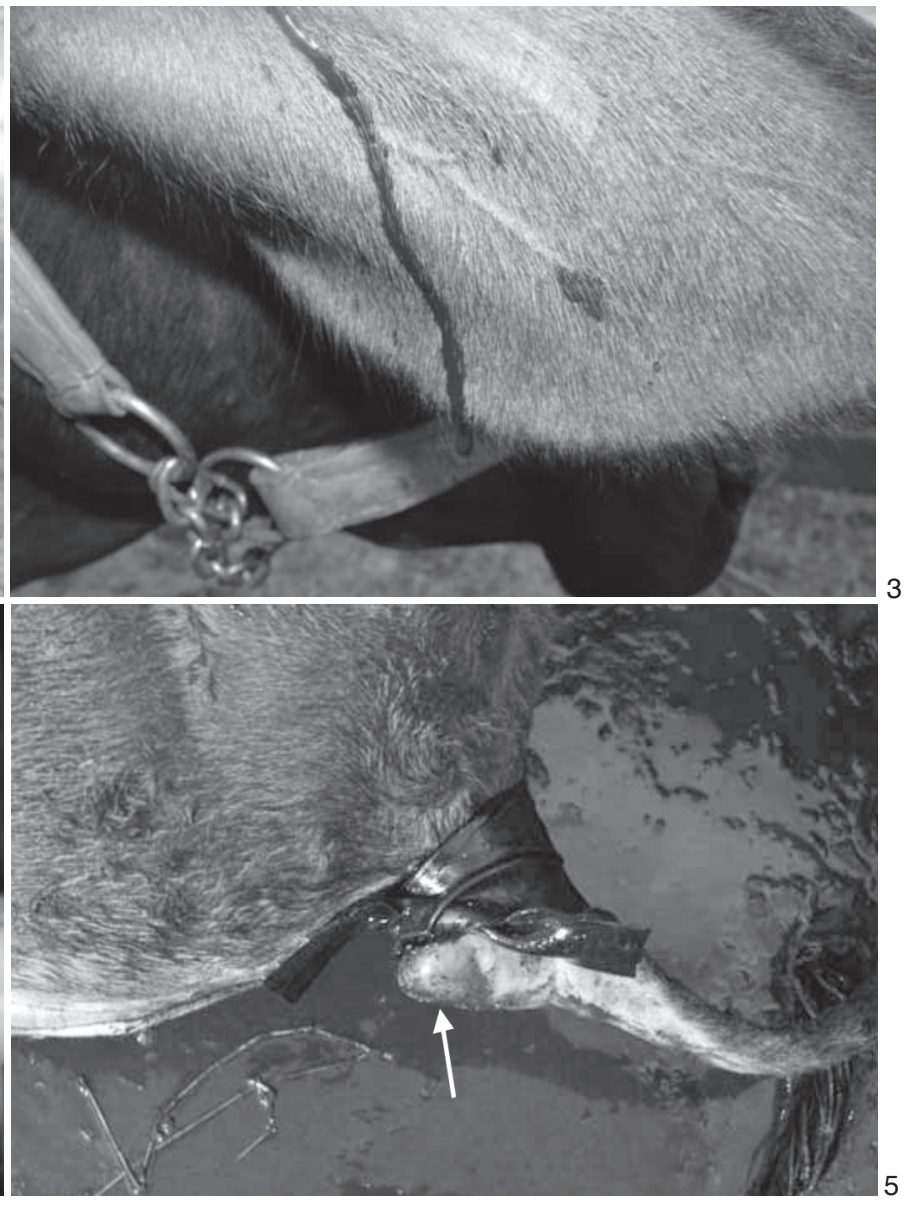

Fig.3. Hemorragia, devido à dificuldade na coagulação sangüínea, após teste do tempo de sangramento (Inoculação subcutânea do veneno no Bovino 5711).

Fig.5. Hematoma subcutâneo (seta) na prega caudal e sangramento (no chão), só contido através de garrote (Inoculação subcutânea do veneno no Bovino 5713). 
sentaram os primeiros sintomas entre 25 minutos e 1 hora 16 minutos após a inoculação. O bovino que recebeu a menor dose $(0,0625 \mathrm{mg} / \mathrm{kg})$ por via subcutânea, não morreu, porém apresentou os primeiros sintomas a partir de 5 horas 30 minutos após inoculação. Nos dois animais que receberam o veneno via intramuscular, os primeiros sintomas foram observados entre 35 e 55 minutos após a inoculação.

\section{Quadro clínico}

Em todos os animais observou-se extenso hematoma centrado no local da inoculação (Fig.2), alterações no tempo de sangramento (Fig.3) e tempo de preenchimento capilar (TPC) e hematomas em diversas partes do corpo devido a traumas por contenção. Em dois animais observaram-se sangramentos em feridas (Fig.4) e em locais com ectoparasitos (bernes e carrapatos). Os bovinos apresentaram hematoma e sangramento também no local da colheita de sangue (Fig.5). Um deles (5711) teve seu qua-

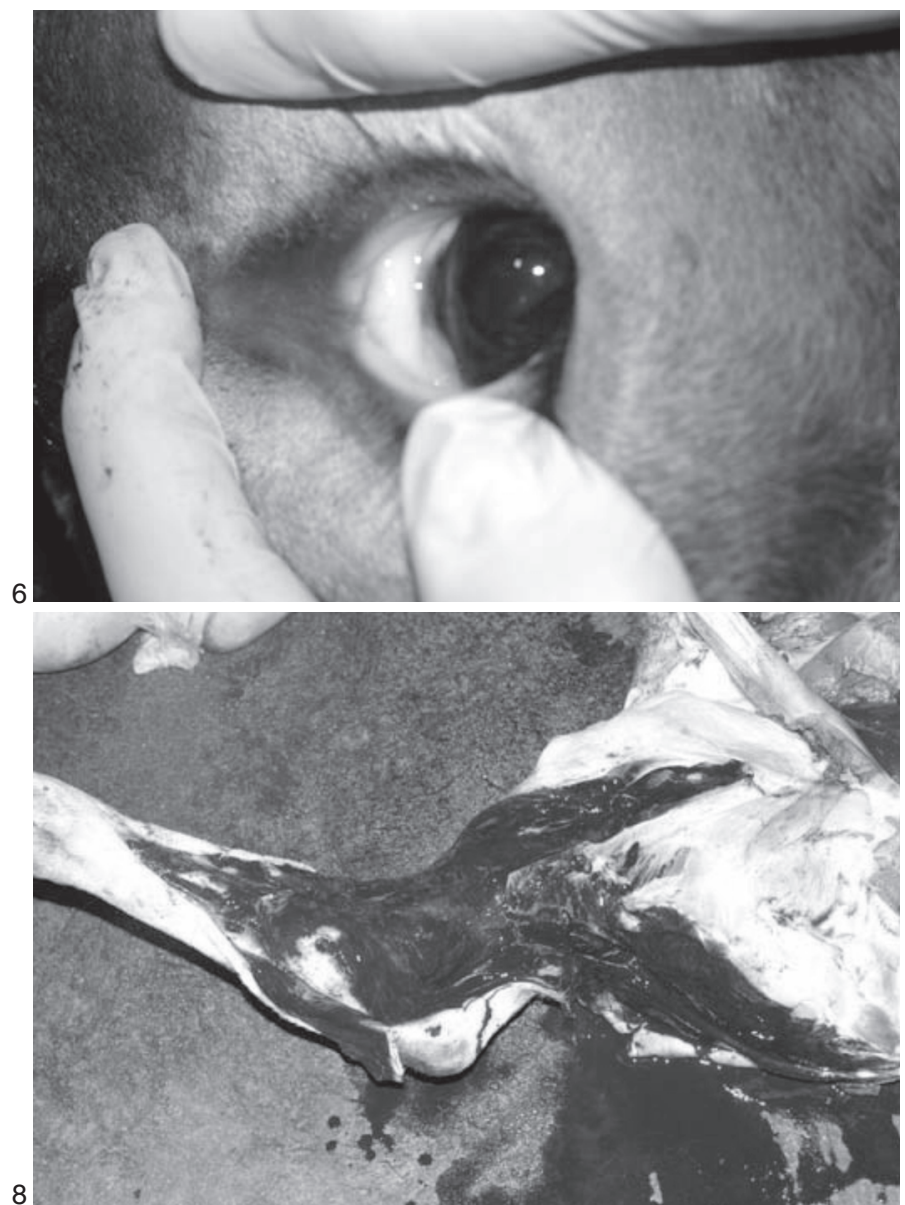

Fig.6. Mucosa ocular marcadamente pálida (Inoculação subcutânea do veneno no Bovino 5713).

Fig.8. Extenso hematoma na subcutis, desde o ponto de inoculação subcutânea do veneno até o boleto (Bovino 5714). dro clínico agravado, pois a colheita foi feita à altura da jugular. A colheita de sangue passou a ser realizada na cauda (veia medial caudal), porém o sangramento continuou a ocorrer, se bem em menor intensidade, porem foi necessário o garroteamento do local para promover a hemostasia (Fig.5).

$\mathrm{Na}$ fase final do envenenamento, os animais exibiram mucosas extremamente hipocoradas (Fig.6), aumento da freqüência cardíaca, dispnéia mista e decúbito esternal; o Bovino 5714 demonstrou falta de apetite e adipsia, além de apatia e atonia ruminal. Bruxismo só foi observado em dois animais (Bov.5711 e 5716).

Não houve mudança significativa nas mensurações de temperatura e freqüência respiratória, com exceção do Bovino 5715, cuja temperatura oscilou entre 39,5 e 41,2 e dos Bovinos 5717 e 5718, com freqüências respiratórias entre 36 e 48. Nos demais, as alterações relativas à temperatura e freqüência respiratória somente ficaram evidentes na fase final do envenenamento. O Bovino 5713
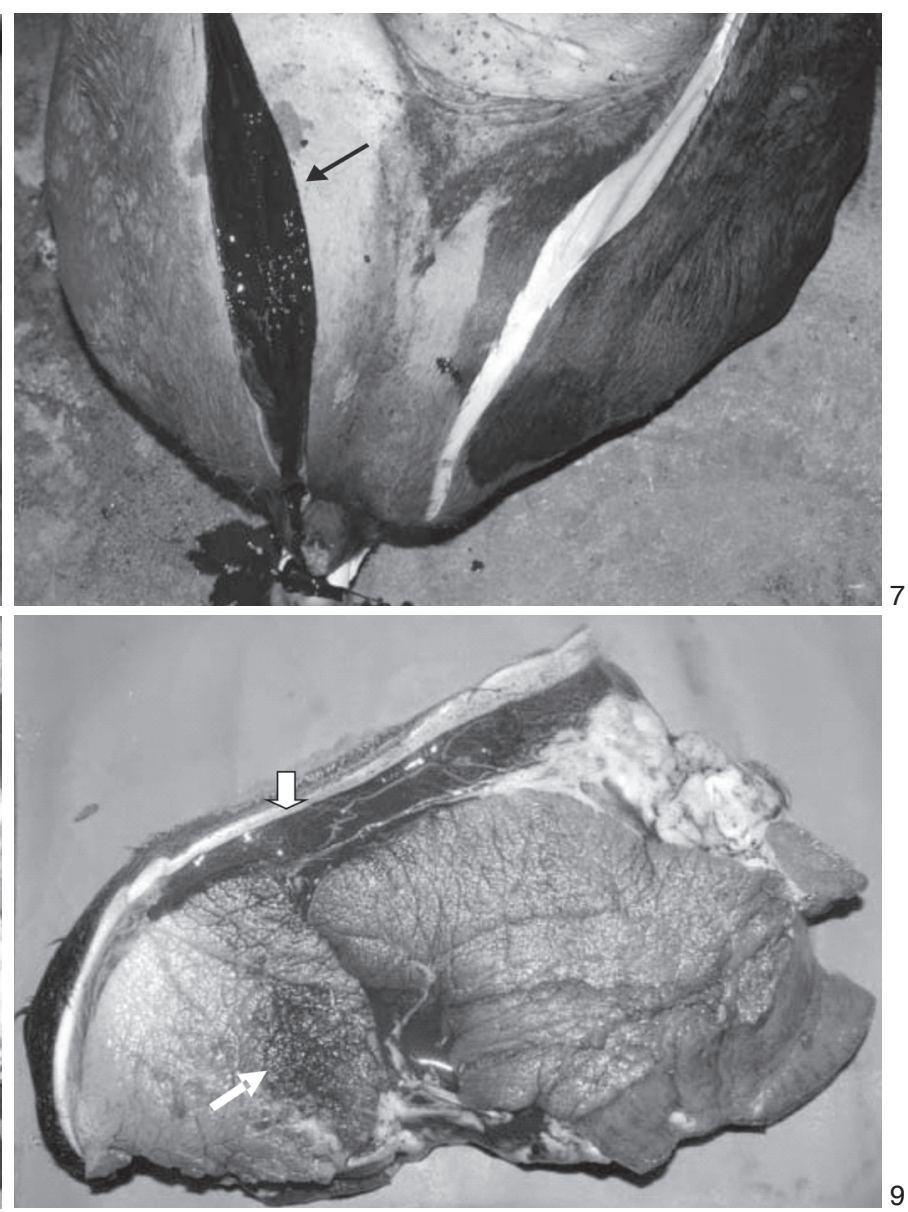

Fig.7. Membro posterior esquerdo (à direita) sem hemorragia, em comparação com o membro posterior direito que exibe extensa hemorragia (seta) a partir do local de inoculação intramuscular do veneno (Bovino 5717).

Fig.9. Hemorragia intramuscular (seta) e mais intensa na subcutis (cabeça de seta) nas adjacências do local de inoculação subcutânea do veneno (Bovino 5711). 
apresentou petéquias e equimoses na gengiva e sangramento nasal (epistaxe) e oral. Hematoquesia foi observado nos Bovinos 5713, 5714 e 5716 e claudicação nos Bovinos 5711, 5717 e 5718. Os Bovinos 5713 e 5714 apresentaram fezes ressequidas.

\section{Hemograma, reticulócitos, proteínas plasmáticas, con- tagem de plaquetas e fibrinogênio}

$\mathrm{Na}$ avaliação do eritrograma verificou-se progressiva anemia normocítica normocrômica entre 6 e 24 horas após a inoculação. Pôde-se observar também moderada diminuição no hematócrito e na concentração de hemoglobina. Os reticulócitos mantiveram-se dentro dos parâmetros fisiológicos da espécie bovina. Proteínas plasmáticas e plaquetas diminuíram moderadamente, com exceção dos Bovinos 5713 e 5716, cujos níveis plaquetários permaneceram dentro da normalidade. Moderada hipofibrinogenemia foi observada em todos os animais. O leucograma apresentou-se com eosinopenia e desvio nuclear de neutrófilos à esquerda.

\section{Bioquímica sérica}

A maioria dos animais apresentou moderado aumento dos níveis de glicose, uréia, creatinaquinase (CK) e dehidrogenase láctica $(\mathrm{DHL})$. Diminuição moderada das proteínas séricas totais foi evidenciada em todos os animais, geralmente, a partir dos tempos 6 e 12, com exceção do Bovino 5711, que apresentou evolução muito rápida.

\section{Urinálise}

Não houve quaisquer alterações macroscópicas ou na análise das amostras de urina.

\section{Avaliação da coagulação sanguínea}

A capacidade de coagulação sanguínea foi avaliada através da coleta de sangue nos tempos $0,2,6,12,24$, 48 horas, após a inoculação e os principais achados estão tabulados no Quadro 2.

\section{Achados de necropsia}

Os principais achados de necropsia encontrados foram extensos hematomas na região subcutânea $(6 / 6,6$ de 6 bovinos) do membro em que foi aplicado o veneno, desde o ponto de inoculação até o boleto (Fig.8) e no interior dos músculos (Fig.10). Nos animais em que a administração do veneno foi por via subcutânea (4/6), as hemorragias na subcutis eram mais extensas (Fig.8), porém na musculatura eram leves (Fig.9), restritas a uma área próxima ao local de inoculação. Por outro lado, os animais que receberam o veneno por via intramuscular (2/6), apresentaram áreas hemorrágicas intramusculares bem mais extensas (Fig.10), e hemorragias subcutâneas menos extensas. Adicionalmente, foram observadas petéquias na serosa do rúmen, omaso, mucosa do abomaso, vesícula biliar, reto e em testículos (6/6) e equimoses e sufusões na serosa do rúmen, retículo e do omaso. Havia também equimoses de conformação longitudinal (víbices) na serosa do retículo (6/6). No interior da cavidade abdominal havia discreta a moderada quantidade de sangue (parte líquido, parte coagulado), as-

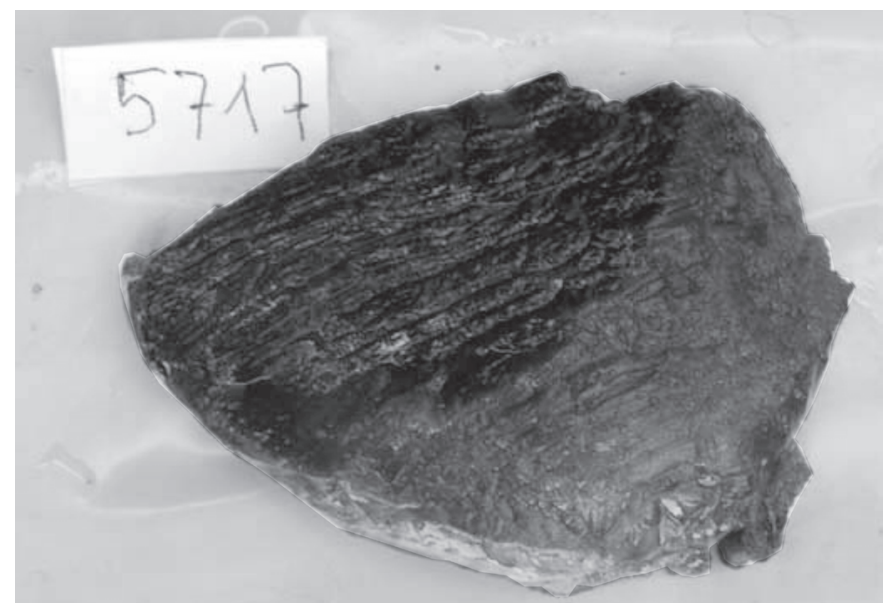

Fig.10. Extensa hemorragia (área mais escura) na musculatura (Inoculação intramuscular do veneno no Bovino 5717).

Quadro 2. Avaliação da coagulação sanguínea: tempo de ativação da protrombina (TAP) e tempo de tromboplastina parcial ativada (TTPA) dos bovinos submetidos ao envenenamento botrópico ${ }^{\mathrm{a}}$

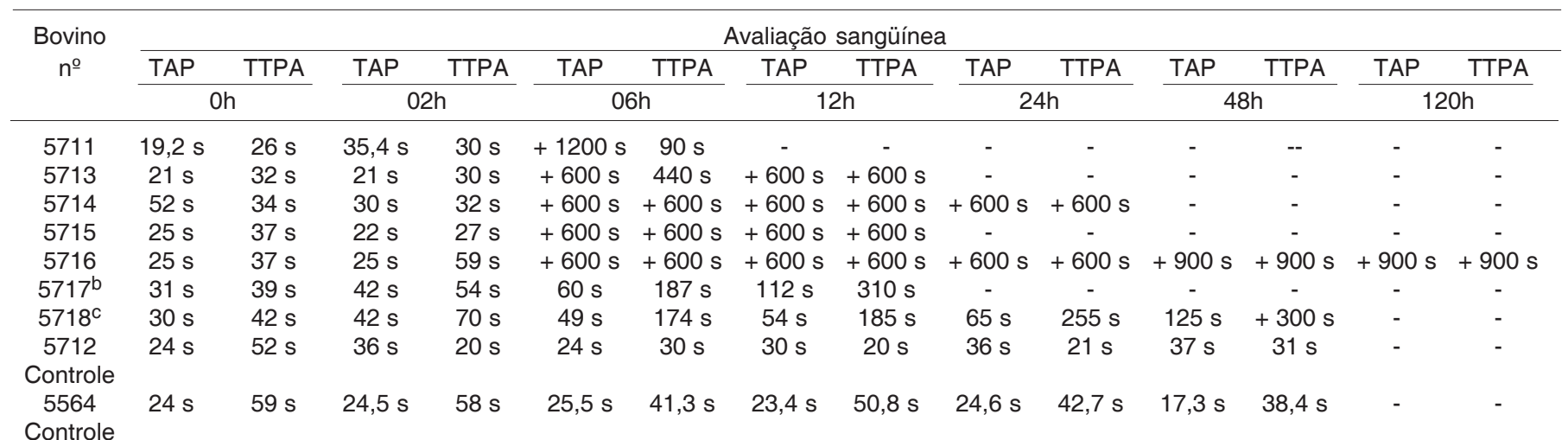

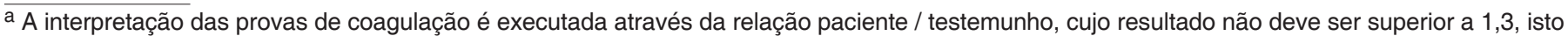
é, o valor deve ser no máximo entre 20 e $30 \%$ superior ao testemunho; ${ }^{\mathrm{b}} 5717$ = última coleta realizada 10 horas após a inoculação; ${ }^{\mathrm{C}} 5718=$ última coleta realizada 34 horas após a inoculação. 
sim como no intestino delgado (3/5), cólon $(5 / 6)$, reto $(5 / 6)$ e bexiga (5/6). Os rins estavam envoltos por grande coágulo (5/6) (Fig.11). As carcaças estavam muito pálidas, assim como o fígado, baço, rins e pulmões (6/6). Hematomas extensos foram verificados no tórax (3/6), entre os músculos intercostais $\left(4^{\circ}\right.$ e $5^{\circ}$ espaços intercostais) e em locais que sofreram traumas (6/6). Os linfonodos poplíteos (6/6) do membro posterior direito (local da inoculação do veneno) e alguns linfonodos da cavidade pélvica (3/6) apresentaram áreas hemorrágicas. Havia extensas hemorragias no endocárdio esquerdo e raras petéquias nas aurículas $(5 / 6)$.

\section{Achados histopatológicos}

Tanto nos animais inoculados por via intramuscular (2/ 6), quanto por via subcutânea (4/6), a principal alteração histopatológica foi hemorragia no local da inoculação e em outros locais já discriminados nos achados necroscópicos.

A necrose muscular, achado importante nos animais que receberam o veneno por via intramuscular (2/6), ca-

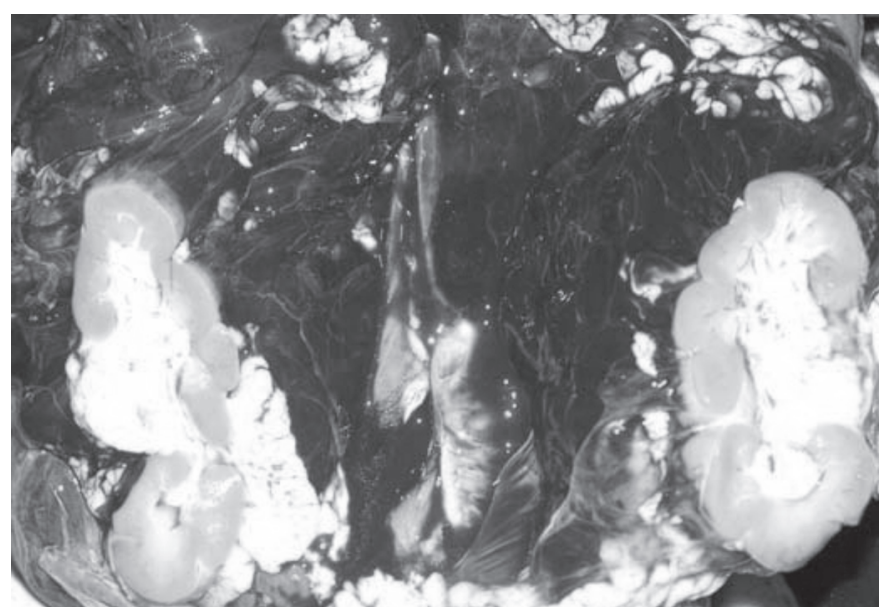

Fig.11. Rim envolto por grande coágulo (Inoculação subcutânea do veneno no Bovino 5714).

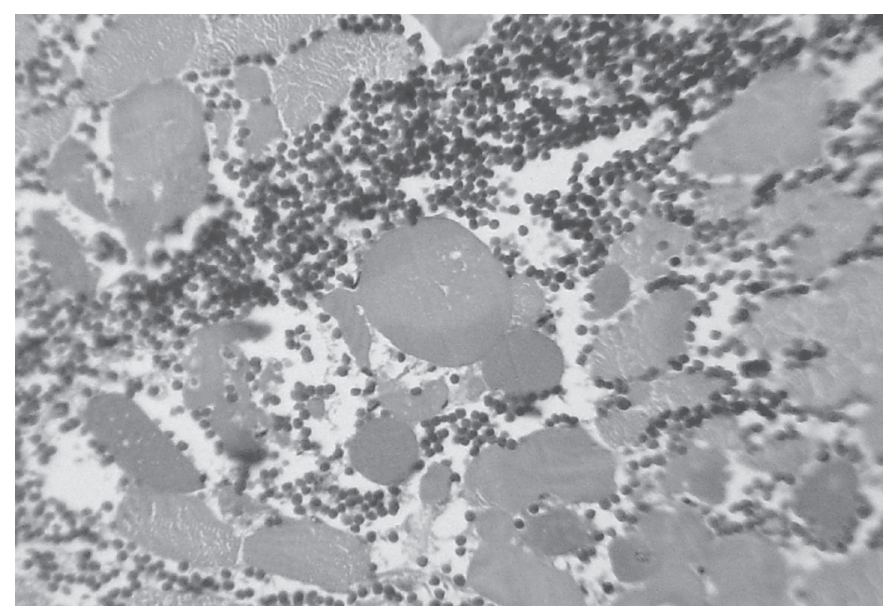

Fig.12. Hemorragia e hialinização (necrose) de fibras musculares (Inoculação intramuscular do veneno no Bovino 5717). HE, obj.25x. racterizava-se por extensas áreas de miócitos com citoplasma marcadamente eosinofílico, vítreo, sem estriação, núcleos picnóticos ou ausentes, em meio às áreas de hemorragia (Fig.12). Adicionalmente observouse, em algumas fibras, degeneração flocular (granular) com formação de grânulos ou massas citoplasmáticas eosinofílicas, por vezes vacuolizadas, em porções de fibras musculares esqueléticas. Ruptura e hipercontração segmentar de fibras (fibras com aspecto "ondulado") também foram observadas. Nos animais que receberam o veneno por via subcutânea (4/6), havia grandes coleções de sangue na subcutis e na derme, porém a hemorragia e a necrose intramusculares eram leves, restritas à proximidade do ponto de inoculação.

Os linfonodos poplíteos adjacentes (6/6) ao local da inoculação, bem como os da cavidade pélvica (3/6) apresentavam grande quantidade de sangue em seios subcapsulares e medulares.

Corpúsculos de choque granulares foram observados nos sinusóides hepáticos de 3 animais (3/6).

Achados adicionais, aparentemente não associados ao efeito direto do veneno, foram presença de cistos de Sarcocystis em músculo esquelético e cardíaco (6/6), discreta pericolangite mononuclear em fígado (6/6), leve congestão hepática (3/6), leve tumefação (1/6) e vacuolização de hepatócitos (2/6), bem como discretas alterações regressivas em algumas células tubulares renais $(3 / 6)$ e em alguns hepatócitos (3/6) (eosinofilia citoplasmática e contração nuclear). Também foram observados cilindros hialinos (3/6) em alguns túbulos renais (albuminúria).

\section{DISCUSSÃO}

\section{Aspectos toxicológicos e de metodologia}

A inoculação do veneno de Bothrops alternatus em bovinos produziu quadro hemorrágico similar ao relatado tanto em casos naturais (Grunert 1967, Grunert \& Grunert 1969, Menezes 1995/96) quanto nos casos experimentais (Novaes et al. 1986, Oliveira et al. 2004a).

Realizamos neste estudo, experimentos auto-direcionados, isto é, os resultados de um experimento direcionaram os subseqüentes, com o intuito de diminuir o número de animais utilizados. Portanto, optamos inicialmente pela dose de $0,25 \mathrm{mg} / \mathrm{kg}$ por via subcutânea, a mesma utilizada por Araújo et al. (1963). Com esta dose, o período de evolução foi muito curto. Diminuímos então a dose para $0,125 \mathrm{mg} / \mathrm{kg}$, que possibilitou uma evolução mais longa, e melhor caracterização do quadro clínicopatológico, embora ainda com $100 \%$ de mortes. A dose foi diminuída novamente à metade, isto é $0,0625 \mathrm{mg} / \mathrm{kg}$, 0 que provocou sintomas moderados e recuperação após 92 horas. Os dois bovinos inoculados com doses de 0,25 e $0,45 \mathrm{mg} / \mathrm{kg}$, por via intramuscular, apresentaram claudicação e ambos evoluíram para a morte.

O prazo para o início dos sintomas foi inversamente proporcional à dose utilizada, da mesma forma que o observado por Araújo et al. (1963). 


\section{Quadro clínico geral}

A formação de hematoma no local da inoculação por via subcutânea ocorreu entre 25 minutos e 5 horas e trinta minutos e caracterizou-se externamente por aumento de volume sob a pele. Nesse ponto, é importante ressaltar que, na literatura em geral, esse aumento de volume é descrito como edema. Em bovinos inoculados com peçonha de $B$. alternatus, trata-se de hemorragia (sangue total) e não edema. Por outro lado, não se pode afirmar que o mesmo ocorre com relação a outros ofídios do gênero Bothrops, nem no que se relaciona a outras espécies envenenadas, uma vez que venenos ofídicos, comprovadamente, podem ter efeitos diferentes em diferentes espécies envenenadas. Tal fato já foi observado em bovinos inoculados com o veneno de Crotalus durissus terrificus, que não desenvolveram mioglobinúria como parte dos humanos envenenados pelo mesmo ofídio (Birgel et al. 1983, Graça 2007). Os animais do presente experimento tornaram-se menos responsivos aos estímulos externos, havia aumento da freqüência cardíaca, dispnéia mista e hipotermia. Estes achados também foram encontrados por Grunert (1967), Grunert \& Grunert (1969), Méndez (2001). As coletas de sangue realizadas $(0,2,6,12,24,48$ horas) após a inoculação agravaram o quadro hemorrágico determinado pelo efeito anti-coagulante do veneno. Um animal apresentou agravamento do quadro clínico devido à colheita de sangue na jugular. Devido a este fato, nos demais animais, o sangue foi colhido na veia medial caudal (cauda), nesse caso a formação de hematoma foi menor e controlada através de garrotes. Para os exames laboratoriais é muito importante que a coleta de sangue seja realizada em uma veia de menor calibre. Hematomas presentes em outras áreas do corpo foram notados, principalmente, em locais de trauma (tronco de contenção), achado também observado por Novaes et al. (1986). Aumento da freqüência cardíaca, mucosas hipocoradas e hipotermia, achados verificados nesse experimento, podem ocorrer em choque hipovolêmico. Neste estudo observamos que o acentuado quadro hemorrágico, determinante para a morte dos animais, levou ao choque hipovolêmico.

A freqüência respiratória apresentou oscilação em dois animais (Bov.5717 e 5718), provavelmente, devido à dor causada pela inoculação do veneno por via intramuscular. A temperatura em um animal (Bov.5715) oscilou entre $39,5^{\circ}$ e $41,2^{\circ} \mathrm{C}$. O comportamento sanguíneo desse animal e o estresse podem ter contribuído para essa alteração (Menezes 1995/96).

O interesse pelo alimento e pela água foi mantido de início em todos animais, com exceção do Bovino 5714, que apresentou anorexia, adipsia, apatia e atonia ruminal na fase final do envenenamento, provavelmente, pelo agravamento do quadro clínico. "Bruxismo", observado em dois aniamis (Bov.5711 e 5716), pode ocorrer em situação de estresse (Thomas 2000).

Havia presença de petéquias e equimoses na gengiva e epistaxe apenas no Bovino 5713; quadro de sangramento nasal e oral também foi observado por Grunert (1967),
Grunert \& Grunert (1969) e Méndez (2001). Grunert (1967), Grunert \& Grunert (1969) e Méndez (2001) verificaram hematoquesia em animais naturalmente envenenados, achado observado em três animais (Bov.5713, 5714 e 5716) do nosso experimento.

Claudicação foi notada em três animais (Bov.5711, 5717 e 5718) e tornou-se mais acentuada com o passar do tempo, principalmente, nos animais que receberam o veneno por via intramuscular. $\mathrm{O}$ mesmo foi observado em casos naturais descritos por Grunert (1967), Grunert \& Grunert (1969) e Méndez (2001).

\section{Resultados laboratoriais}

$\mathrm{Na}$ avaliação do eritrograma verificou-se anemia normocítica normocrômica, ocasionada pelas hemorragias que variou de discreta a acentuada, entre 6 e 24 horas, após a inoculação. Esta alteração também foi observada por Oliveira et al. (2004b). O quadro hemorrágico causou uma moderada diminuição do hematócrito e da concentração de hemoglobina. Houve moderada diminuição de plaquetas e proteínas plasmáticas com exceção dos Bovinos 5713 e 5716 , cujos níveis plaquetários permaneceram dentro da normalidade. A trombocitopenia observada na maioria dos animais é decorrente da ação de enzimas como trombocitina e L-amino oxidase, responsáveis pela indução da agregação plaquetária. A diminuição das proteínas séricas totais está relacionada com as intensas hemorragias provocadas pelo envenenamento botrópico. Este fenômeno pode ser explicado pela ação da enzima tipo trombina, encontrada no veneno, que consome parte do fibrinogênio circulante.

Havia discreta leucocitose caracterizada por neutrofilia, monocitose, linfopenia e eosinopenia, que pode estar associada ao estresse. $\mathrm{O}$ discreto desvio de neutrófilos à esquerda (aumento de bastões), observado em todos os animais, pode estar associado ao processo inflamatório agudo no local da inoculação.

Todos os animais apresentaram moderado aumento dos níveis de glicose, uréia, creatinaquinase (CK) e dehidrogenase láctica (DHL). Os níveis séricos de glicose e uréia sofreram aumento, possivelmente, devido ao estresse. Barraviera \& Pereira (1994) observou que CK e ASAT podem sofrer discretos aumentos decorrentes de lesões musculares causadas pelo envenenamento botrópico. Por outro lado, Alencar \& Servaes (1994) averiguaram que o aumento de CK também pode ser decorrente de traumatismo muscular e quadro de choque. Em casos de choque, a hipotensão diminui o débito cardíaco e aumenta a produção de lactato, que por sua vez termina por lesar as fibras musculares; quanto maior o tempo em que o indivíduo fica em choque, maiores serão as lesões tissulares e os níveis de CK (Cecil et al. 2005).

Verificou-se progressivo aumento do tempo de sangramento, alteração descrita em bovinos também por Menezes (1995/96). O tempo de ativação da protrombina (TAP) e tempo de tromboplastina parcial ativada (TTPA) estavam moderadamente aumentados. O aumento do TAP e do TTPA indica que as vias intrínseca e extrínseca foram com- 
prometidas e, conseqüentemente, a via comum. Não houve quaisquer alterações na urina (clínica e urinálise).

\section{Achados de necropsia}

Verificamos alterações macroscópicas significativas que, quando associadas ao histórico, permitem fornecer subsídios para diagnóstico de provável envenenamento botrópico. Contudo, aparentemente, não se pode estabelecer qual serpente do gênero é a causa do acidente, a menos que haja comprovação de que o animal foi picado por aquela espécie de Bothrops encontrada no local. Os animais que receberam o veneno por via subcutânea apresentaram extensa área hemorrágica/hematoma no tecido subcutâneo que atingia desde o ponto de inoculação até o boleto. Nesses animais, hemorragias intramusculares ocorreram somente em uma pequena área próxima ao ponto de inoculação, provavelmente, pela distribuição do veneno ser maior no tecido subcutâneo. Nos animais em que o veneno foi inoculado por via intramuscular, também havia hematomas subcutâneos, porém menos extensos; nesse caso a maior quantidade de sangue encontrava-se dentro do músculo inoculado. Grunert (1967), Grunert \& Grunert (1969) e Novaes et al. (1986) também evidenciaram hematomas no tecido subcutâneo, porém Novaes et al. (1986) os interpretaram como "edema" sero-hemorrágico subcutâneo. O termo hematoma não é utilizado na maioria dos trabalhos; os autores empregam a palavra "edema", não só em bovinos, mas também em humanos e em outros animais (Araújo et al. 1963, Novaes et al. 1986, Barraviera \& Pereira 1994, Menezes 1995/96, Pérez et al. 1997, Ribeiro \& Jorge 1997, Bicudo 1999, Teibler et al. 1999, Méndez 2001). Como já discutido no quadro clínico geral, pelo menos em relação ao envenenamento de bovinos por $B$. alternatus, trata-se de hematoma e não edema.

Outro aspecto interessante é o fato das carcaças e órgãos de todos os animais necropsiados apresentarem-se muito pálidos em virtude da hemorragia e do desenvolvimento de choque hipovolêmico. Todas estas desordens hemorrágicas podem ser causadas, provavelmente, por degradação dos fatores de coagulação (X, II, VIII) (Nahas et al. 1979, Souza et al. 2000, Cominetti et al. 2003) e comprometimento plaquetário (trombocitopenia). Os linfonodos do membro em que foi realizada a inoculação encontravam-se com aspecto hemorrágico, ao que tudo indica por drenarem sangue das áreas hemorrágicas adjacentes.

\section{Achados histopatológicos}

A via subcutânea produziu uma leve necrose nos músculos próximos à inoculação, provavelmente, devida à difusão do veneno pela área (Araújo et al. 1963). Por outro lado, a inoculação do veneno por via intramuscular, causou acentuada hemorragia e necrose no interior dos músculos próximos ao ponto de inoculação, alteração já verificada em bovinos por Araújo et al. (1963) e Oliveira et al. (2004a). A necrose coagulativa com hialinização das fibras musculares, possivelmente, está associada à hipóxia celular e à compressão, ocasionada pela intensa hemorra- gia, que impede a adequada oxigenação dos tecidos nessa área.

As alterações regressivas observadas, no fígado e nos rins, não foram consideradas significativas e nem relacionadas diretamente ao efeito do veneno botrópico. Lesões semelhantes têm sido observadas em quadros de choque (Jones et al. 1996).

\section{Diagnóstico diferencial}

Existem enfermidades que apresentam manifestações clínicas semelhantes às verificadas no envenenamento botrópico em bovinos; por este motivo, é muito importante obterem-se informações detalhadas do histórico e do quadro clínico-patológico.

No que se refere aos aspectos epidemiológicos, faz-se necessário o conhecimento da distribuição geográfica e o habitat das serpentes. Por exemplo, na Região Norte, muitas pessoas associam o acidente ofídico às mortes súbitas em bovinos, porém, segundo Tokarnia \& Peixoto (2006) há uma superestimação de casos. Nessa região, a maior parte das mortes em bovinos está relacionada à ingestão de plantas tóxicas, principalmente, das que causam morte súbita. $B$. alternatus, a serpente mais peçonhenta do gênero Bothrops, não ocorre na região Amazônica As duas serpentes venenosas que poderiam ser incriminadas, seriam $B$. atrox, que tem ampla distribuição na Amazônia, mas não produz veneno suficiente para matar um bovino adulto (Araujo et al. 1963) e Crotalus durissus terrificus, que produz veneno em quantidade suficiente para matar um bovino adulto, porém só é encontrada em pequenos nichos que não compreendem mais de $1 \%$ da região.O quadro clínico do envenenamento botrópico em bovinos constitui-se basicamente por sintomatologia hemorrágica, de evolução rápida. Por esse motivo, a diátese hemorrágica $(\mathrm{DH})$ causada pela ingestão de Pteridium aquilinum, deve ser levada em consideração no diagnóstico diferencial. A DH cursa com evolução superaguda a subaguda e está associada à ingestão de brotos de samambaia; esta intoxicação acomete principalmente animais de até 2 anos de idade (França et al. 2002). A intoxicação por derivados cumarínicos também caracteriza-se por quadro hemorragíparo, entretanto, não há aumento de volume localizado (local da picada) (Brito et al. 2005).

Carbúnculo sintomático é uma enfermidade aguda, muito comum em bezerros de 6 meses a 2 anos, e causa quadro de miosite hemorrágica grave (Riet-Correa 2001). Segundo Tokarnia \& Peixoto (2006) é possível que carbúnculo sintomático tenha sido diagnosticado como acidente ofídico, principalmente, pelo aumento do volume que ocorre na massa muscular e / ou no tecido subcutâneo de bovinos. No entanto, a área afetada apresenta-se crepitante (presença de gás) e com odor butírico ao corte, além de presença de líquido hemorrágico com fibrina em cavidades (Riet-Correa 2001).

Carbúnculo hemático é uma doença rara em nosso meio, porém mesmo assim ainda há uma tendência de se associar suas alterações ao acidente ofídico, devido à semeIhança de alguns achados clínicos (Langenegger 1994). 
Entretanto, no carbúnculo hemático, além das hemorragias, há rápida tumefação da carcaça por distensão gasosa, edema na garganta, esterno, períneo e flanco e baço amolecido e muito aumentado de volume (Fernandes 2001, Schild et al. 2006).

No caso dos traumas em indivíduos "sadios" a característica principal é o edema e em alguns casos, dependendo da intensidade da lesão, áreas hemorrágicas restritas; no acidente ofídico o hematoma no local da picada é acentuado.

Este estudo indica que exemplares de $B$. alternatus, caso inoculem todo seu veneno, poderiam levar bovinos adultos à morte. Por outro lado, pelo fato de ofídios serem capazes de regular a quantidade de veneno inoculada e, possivelmente, não "considerarem" bovinos como presa potencial, é provável que o número de acidentes nessa espécie seja pequeno, o que está de acordo com o observado na maioria dos centros diagnóstico anátomo-patológico no país.

\section{REFERÊNCIAS}

Alencar R.A. \& Servaes C.R. 1994. Guia para o diagnóstico em medicina veterinária. Editora Nobel, São Paulo. 205p.

Araujo P. \& Belluomini H.E. 1960-1962. Toxicidade de venenos ofídicos. I. Sensibilidade específica de animais domésticos e de laboratório. Mem. Inst. Butantan 30:143-156.

Araujo P., Rosenfeld G. \& Belluomini H.E. 1963. Toxicidade de venenos ofídicos. II, Doses mortais para bovinos. Arqs Inst. Biológico, São Paulo, 30:43-48.

Barraviera B. 1994. Venenos Animais: uma visão integrada. EPUB, Rio de Janeiro. 411p.

Barraviera B. \& Pereira P.C.M. 1994. Acidentes por serpentes do gênero "Bothrops", p.261-280. In: Barraviera, B. (ed.), Venenos Animais: uma visão integrada. EPUB, Rio de Janeiro.

Barraviera B. 1999. Ofídeos: estudos clínicos dos acidentes. EPUB, Petrópolis. 411p.

Belluomini H.E., Araujo P., Rosenfeld G. \& Penha A.M. 1983. Beitrag zur Serumtherapie bei experimenteller Vergiftung von Rindern mit dem Gift der Klapperschlange. Dtsch. Tierärztl. Wochenschr. 90:93-95.

Berrocal A., Gutierrez J.M. \& Estrada R. 1998. Snake envenomation in bovine. Large Anim. Pract. 19(4):26-27.

Bicudo P.L. 1994. Acedentes ofídicos em Medicina Veterinária, p.375387. In: Barraviera D. (ed.), Venenos Animais: uma visão integrada. EPUC, Rio de Janeiro.

Birgel E.H., Belluomini H.E. \& Leinz E.E. 1983. Auswertung der Urinbefunde bei Rindern mit experimenteller Crotalus-Vergiftung. Zbl. Vet. Med. 30:283-289.

Brito M.F., Seixas J.N., Jabour F.F., Andrade G.B., Cunha B.R.M., França T.N. \& Peixoto P.V. 2005. Sobre um surto de envenenamento por derivado cumarínico em bovinos. Pesq. Vet. Bras. 25(3):143-149.

Cecil R.L., Goldman L. \& Ausiello D. 2005. Tratado de Medicina Interna. Vol.2. $22^{\mathrm{a}}$ ed. Elsevier Editora, Rio de Janeiro. 2776p.

Cominetti M.R., Ribeiro J.U., Fox J.W. \& Selistre-de-Araujo H.S. 2003. BAG, a new dimeric metalloproteinase/disintegrin from the Bothrops alternatus snake venom that interacts with $\alpha 2 \beta 1$ integrin. Arch. Biochem. Biophys. 416(2):171-179.

Fernandes C.G. 2001. Doenças Bacterianas: Carbúnculo hemático, p.206-213. In: Riet-Correa F., Schild A.C., Méndez M.D.C. \& Lemos R. (ed.), Doenças em Ruminantes e Eqüinos. Vol.2. 2ª ed. Varela Editora, São Paulo.

França T.N., Tokarnia C.H. \& Peixoto P.V. 2002. Enfermidades determinadas pelo princípio radiomimético de Pteridium aquilinum (Polypodiaceae). Pesq. Vet. Bras. 22(3):85-96.
Graça F.A.S. 2007. Aspectos clínico-patológicos e laboratoriais do envenenamento crotálico experimental em bovinos. Tese de Doutorado em Ciências Veterinárias, Universidade Federal Rural do Rio de Janeiro. $109 p$

Grunert E. 1967. Beobachtungen über Schlangenbissverletzungen bei grossen Haustieren in Süd-Brasilien. Dtsch. Tierärztl. Wochenschr. 74(20):531-532.

Grunert E. \& Grunert, D. 1969. Beobachtungen von "Bothrops"Schlangenbissverletzungen bei Rind und Pferd in Rio Grande do Sul, Brasilien. Vet. Med. Nachrichten 3:217-232.

Jones T.C. Hunt R.D. \& King N.W. 1996. Veterinary Pathology. 6th ed. Lippincott Williams and Wilkins, Philadelphia 1392p.

Langenegger J. 1994. Ocorrência do carbúnculo hemático em animais no Brasil. Pesq. Vet. Bras. 14(4):135-136.

Melgarejo A.F. 2003. Serpentes peçonhentas do Brasil, p.33-61. In: Cardoso J.L.C., França F.O.S., Wen F.H., Málaque C.M.S. \& Haddad J.R.V. (ed.), Animais peçonhentos do Brasil: biologia, clínica e terapêutica dos acidentes. Sarvier Editora, São Paulo.

Méndez M.D.C. 2001. Doenças tóxicas: envenamento botrópico, p.169176. In: Riet-Correa F., Schild A.C., Méndez M.D.C. \& Lemos R. (ed.), Doenças em Ruminantes e Eqüinos. Vol.2. $2^{\mathrm{a}}$ ed. Varela Editora, São Paulo.

Menezes R.V. 1995/96. Ofidismo em bovinos. Arq. Esc. Med. Vet., Salvador, 18(1):224-231.

Nahas L., Kamiguti A.S. \& Barros A.R. 1979. Thrombin-like and factor X-activator components of Bothrops snake venoms. J. Thromb. Haemost. 41:314-328.

Novaes A.P., Lucas S., Abe A.S., Fernandes W., Puorto G. \& Almeida I.L. 1986. Envenenamento botrópico em bovinos: tratamento opcional. Circ.Téc.3, Embrapa, UEPAE São Carlos, SP. 29p.

Oliveira N.J.F., Melo M.M., Ribeiro E.L., Lago L.A. \& Lucia M. 2004a. Achados histopatológicos em bovinos experimentalmente envenenados com veneno de Bothrops alternatus. XXXI Conbravet, São Luiz, MA. (Resumo)

Oliveira N.J.F., Ribeiro E.L., Silva J.P.G.P., Lago L.A., Lucia M. \& Melo M.M. 2004b. Bovine blood profile after Bothrops alternatus envenenomation. VIII Congr. Soc. Bras. Toxinologia, Angra dos Reis, RJ. (Resumo)

Pérez O.C.A., Koscinczuk P., Flinta S.M., Maidana H.R. \& Negrete M.S. 1997. Bothrops alternatus envenoming in young dogs. J. Venom. Anim. Toxins 3(1):43-47.

Ribeiro L.A. \& Jorge M.T. 1997. Acidente por serpentes do gênero Bothrops: série de 3139 casos. Revta Soc. Bras. Med. Trop. 30(6):475480.

Riet-Correa F. 2001. Doenças bacterianas: Carbúnculo sintomático, p.213-216. In: Riet-Correa F., Schild A.C., Méndez M.D.C. \& Lemos R. (ed.), Doenças em Ruminantes e Eqüinos. Vol.2. $2^{\mathrm{a}}$ ed. Varela Editora, São Paulo.

Schild A.L., Sallis E.S.V., Soares M.P., Ladeira S.R.L., Schramm R., Priebe A.P., Almeida M.B. \& Riet-Correa F. 2006. Anthrax in cattle in southern Brazil: 1978-2006. Pesq. Vet. Bras. 26(4):243-348.

Souza D.H.F., lemma M.R.C., Ferreira L.L., Faria J.P., Oliva M.L.V., Zingali R.B., Niewiarowski S. \& Selistre-de-Araújo H.S. 2000. The disintegrin-like domain of the snake venom metalloprotease alternagin inhibits $\alpha 2 \beta 1$ integrin-mediated cell adhesion. Arch. Biochem. Biophys. 384(2):341-350.

Teibler P., Pérez O.A., Maruñaque S., Ruiz R., Koscinczuk P., Sánchez Negrette M. \& Mussart de Coppo N. 1999. Lesiones locales y sistemicas inducidas por veneno de Bothrops alternatus (víbora de la cruz) de Argentina. Acta. Toxicol. Argent. 7(1):7-10.

Thomas C.L. 2000. Dicionário Médico Enciclopédico Taber. $17^{a}$ ed. Manole Editora, São Paulo. 2279p.

Tokarnia C.H. \& Peixoto P.V. 2006. Importância dos acidentes ofídicos como causa de mortes em bovinos no Brasil. Pesq. Vet. Bras. 26(2):5568. 